\title{
O CLIMA URBANO DAS CIDADES E SUAS INTERAÇÕES COM A ARQUITETURA E A GEOGRAFIA
}

\author{
Thyago Phellip França Freitas \\ Doutorando em Ambiente Construído e Patrimônio Sustentável - UFMG \\ thyagophellip@ceulp.edu.br
}

\section{Resumo}

O clima de uma cidade pode ser entendido como a inter-relação de variáveis que contribuem e interferem na qualidade de vida de uma população. Sendo assim, quando se aborda o clima urbano de uma cidade, busca-se descrever o comportamento climático de determinado local sob a ótica do recorte de escala, delineando o objeto na procura de causa-efeito de determinado perfil climatológico. Monteiro (1976) propôs o SCU (Sistema Clima Urbano) como um método de pesquisa climatológica, inquirindo o comportamento do clima sob os aspectos da termodinâmica, hidro meteórica e físico-química. Desde a publicação do SCU até o presente momento, várias foram as proposições de geógrafos no intuito de entender os comportamentos climatológicos de várias cidades, bem como este também é o campo de interesse dos arquitetos e urbanistas na tentativa de realizar propostas que visem o conforto urbano da cidade em uma escala microclimática, e consequentemente o planejamento urbano em uma escala local. Este estudo utilizou-se de revisão de literatura acerca da temática abordada, além da observação e análise dos impactos e interferências das questões climáticas nas cidades, além ainda de uma análise sobre o modelo do S.C.U., e suas implicações urbanas Cabe destacar que os resultados alcançados nesta pesquisa, a qual abrange a interdicisplinaridade entre as áreas, poderão ser utilizados como subsídio para novas pesquisas com o mesmo intuito de analisar as inter-relações entre geógrafos e arquitetos e urbanistas.

Palavras Chave: Clima Urbano, Cidade, Climatologia, Sistema Clima Urbano.

\section{THE URBAN CLIMATE OF CITIES AND ITS INTERACTIONS WITH ARCHITECTURE AND GEOGRAPHY}

\begin{abstract}
The climate of a city can be understood as the interrelationship of variables that contribute and interfere in the quality of life of one population. Thus, when approaches the urban climate of a city, seeks to describe the climatic behavior of a particular place under the optics of the scale cut, delineating the object in the search for cause-effect of a certain climatological profile. Monteiro (1976) proposed the SCU (Urban Climate System) as a method of climatological research, inquiring the behavior of the climate under the thermodynamic, meteoric and physico-chemical aspects. Since the publication of the SCU up to the present time, several proposals have been made by geographers in order to understand the climatological behavior of several cities, and this is also the field of interest of architects and urbanist in the attempt to make proposals aimed at urban comfort of the city on a microclimatic scale, and consequently urban planning on a local scale. This study used a
\end{abstract}

Recebido em 04/11/2015 / Aprovado para publicação em 05/09/2018.

OBSERVATORIUM: Revista Eletrônica de Geografia, v. 9, n. 3, p. 262-272. set./dez. 2018. 
review of the literature on the subject, as well as the observation and analysis of the impacts and interferences of the climatic issues in the cities, as well as an analysis of the SCU model and its urban implications. It should be noted that the results achieved in this research, which covers the interdicisplinarity between the areas, could be used as subsidy for new researches with the same intention to analyze the interrelations between geographers and architects and urbanists.

Keywords: Urban Climate, City, Climatological, Urban Climate System.

\section{Introdução}

Cidade é o meio físico onde o homem habita por natureza, onde neste espaço busca desenvolver toda a sua trajetória de vida. Sendo assim, este espaço pode ser entendido como uma "derivação antrópica do ambiente" (MONTEIRO, 1990, p.10). É o local onde o homem vive e estabelece suas relações e ligações, transformando-o a seu critério e influenciando-o diretamente pela sua ação.

Atuando neste espaço e buscando a sua dinamização e desenvolvimento, o homem acaba por utilizar de "artifícios" que são 'danosos' ao meio, o que colabora para a transformação do clima urbano da cidade. Monteiro (2006, p. 102) destaca que a análise do ar para os estudos de clima urbano deve ser "air within city", ou seja, o ar transformado dentro da cidade, ao contrário dos meteorologistas que estudam o "air over city", o ar acima da cidade, o que implica em dizer que as ações antrópicas influenciam essa dinâmica do clima.

O clima urbano pode ser caracterizado como um sistema complexo dotado de diversas variáveis que influenciam direta e indiretamente o ambiente, onde a soma das partes pode não ser o todo, além do que, as saídas (outputs) não são necessariamente provenientes das entradas (inputs) dentro do sistema, ou seja, as variáveis diretas no sistema nem sempre correspondem às variáveis de saída, devido as transformações e mudanças ao longo do processos dentro deste sistema complexo.

Por buscar entender essa dinâmica, Monteiro (1976, 2003, p.15) evidenciou, por meio de uma proposta metodológica, o SCU (Sistema Clima Urbano) que é um sistema que busca correlacionar os elementos que interferem no clima urbano de uma determinada cidade.

Deste modo, o clima urbano pode ser entendido por meio do SCU, levando-se em conta o caráter dinâmico do clima e sua relação com o meio urbano, o qual será abordado no tópico a seguir. 
Thyago Phellip França Freitas

\section{A Cidade e o Clima}

Benévolo (2009) argumenta que a cidade é a mais expressiva manifestação do ser humano no planeta - habitar e satisfaz a uma necessidade primária, o mesmo se protegia por meio de espaços naturais até atingir um nível de desenvolvimento que o levou a desenvolver tecnologias para atender a essas necessidades primárias de habitar. Os espaços urbanos refletem as experiências humanas de suprir suas necessidades básicas e ao mesmo tempo conviver harmônica com o meio ambiente.

A cidade tem ou deveria ter seu caráter dinâmico e criacionista para o bem-estar da população (BORJA E CASTELLS, 1996). O crescimento das cidades é resultado de processos antrópicos de ocupação do solo de modo exponencial e, portanto, estes são subsídios contundentes para a formação do clima urbano.

Barbugli e Roriz (2005) destacam que ao construir e ocupar as cidades, o homem interfere significativamente no ambiente climático. Almeida (2006) defende que, dependendo das decisões os resultados dessa interferência serão favoráveis ou prejudiciais à vida, Monteiro (1990) destaca que urbanização é o processo de implantação humana concentrada em um dado lugar. Cabe ressaltar que a urbanização, além de organizar os lugares, ameniza os impactos da interferência humana e contribui para minimizar os efeitos negativos dessa interferência na qualidade de vida das pessoas.

Segundo Assis (2006) acerca da morfologia urbana, a mesma defende que os materiais utilizados nas superfícies juntamente com o calor antropogênico geram diferenças entres os climas urbanos das cidades. Sendo assim estas alterações entre as superfícies associadas aos climas, apresentam mudanças no que tange ao aquecimento e ventilação, o que segundo Monteiro (1990) compreender as relações do ar dentro da cidade e com o fato específico da condição urbana proposta podem auxiliar no entendimento do acontece no espaço citadino.

Monteiro (1986) destaca ainda que o sítio físico da cidade tem um papel importante na determinação da estrutura térmica urbana em áreas tropicais e, desta forma, as conformações urbanas associadas à topografia local ajudam, em sua maioria, na explicação de fenômenos e fatores de aquecimento e resfriamento urbano.

Landsberg (1981) destaca que o aquecimento das superfícies terrestres são reflexos de mudanças microclimáticas em decorrência das alterações da superfície urbana efetuadas pelo homem, o que reforça que estas alterações são relacionadas com as mudanças do balanço de energia e radiação que acontecem na zona urbana. Sendo assim, cada cidade possui uma 
Thyago Phellip França Freitas

especificidade em termos climáticos com seus elementos internos, bem como o arranjo de seu próprio SCU.

Romero (1988) destaca que os fatores climáticos são característicos e marcantes, e que determinam e promovem a origem do clima urbano. Monteiro (2003) explica que tais características são componentes internos do SCU, que determinam os fluxos de energia e matéria. Neste ensejo percebe-se claramente a influência dos elementos e fatores climáticos associados ao fator antrópico sobre o clima urbano das cidades, com uma das variáveis desta "equação urbana".

\section{Subsídio ao aparato metodológico}

Os espaços urbanos são elementos complexos de se estudar, vez que, há vários fatores a serem considerados em sua "equação urbana" e entender o processo dinâmico dos espaços citadinos é essencial para os pesquisadores que se relacionam com o clima urbano, sendo assim, entender as modificações que acontecem no interior da cidade foi um questionamento feito por Monteiro (2003) para entender a dinâmica do clima urbano e sua relação com o meio citadino, além de destacar ainda que os estudos sobre o clima urbano podem ajudar na progressão de ações no campo de conforto térmico nas cidades (MONTEIRO 1990)

Monteiro (1976, 2003) buscou nas teorias de Landsberg (1956) e Chandler (1965) subsídios para seus estudos, contudo fez críticas sobre a forma como os mesmos dispunham seus aparatos teóricos. Enquanto o primeiro autor argumenta acerca das proposições mais fundamentadas na Meteorologia, o segundo opta por estudar todos os elementos climáticos separados, acaba não fazendo a justaposição em busca de um resultado comum, o que inviabiliza o entendimento do clima urbano, pois os elementos pesquisados por ambos devem fazer parte do Clima Urbano sem dissociação.

Com o propósito de agregar os pontos fortes de cada proposição apresentada e buscando elaborar uma nova teoria completamente baseada no clima tropical, em detrimento dos autores referenciados anteriormente, Monteiro (1976) buscou na obra de Bertalanffy (1950), por meio da T.G.S. (Teoria Geral dos Sistemas) a explicação mais plausível para as transformações ocorridas no meio urbano com vistas a entender como estes elementos estão associados e interligados no entendimento dos processos urbanos.

Deste modo, na composição do método ainda encontrou dificuldades acerca da hierarquia à qual seria estabelecida a proposta. Baseando-se em Koestler (1969, citado por MONTEIRO, 1976; 2003) e sua discussão sobre o Holón (hierarquização) e sistema aberto, 
Monteiro (2003) incorporou o SOHO (Self-regulation Open Hierarchic Order) à composição metodológica, buscando evidenciar a dinamização que sofre o clima urbano ao adentrar no espaço citadino, ou seja, o sistema de hierarquia de maior grandeza relaciona-se com o de menor ou de igual grandeza ao nível vertical e horizontal, tornando-o assim aberto, conforme figura 1.

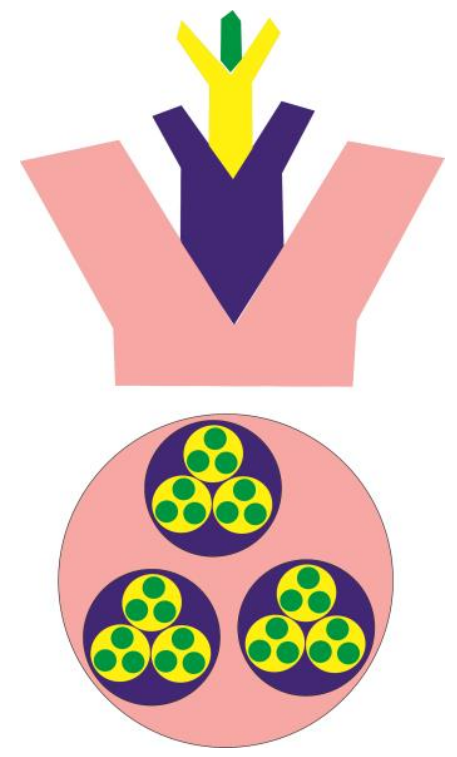

Figura 1: Esquema de hierarquização do Hólon segundo Koestler Fonte: Monteiro, 2003, adaptado pelo autor, 2014.

O Sistema Clima Urbano, portanto, é um sistema de autorregulação, ou seja, as proposições se autoajustam de modo que o equilíbrio no sistema se mantenha, sem haver problemas que abalem a sua estrutura. Monteiro (2003, p. 19) estabeleceu ainda 10 proposições que demonstram como o método foi ordenado, bem como este deve seguir e comportar-se na análise, que são:

1. O clima urbano é um sistema que abrange o clima de um dado espaço terrestre e sua urbanização.

2. O espaço urbanizado que se identifica a partir do sítio, constitui o núcleo do sistema que mantém as relações íntimas com o ambiente regional imediato em que se insere.

3. O SCU importa energia através do ambiente, é sede de uma sucessão de eventos que articulam diferenças de estados, mudanças e transformações internas, a ponto de gerar produtos que se incorporam ao núcleo e/ou são expostas para o ambiente, configurando-se como um todo de organização complexa que se pode enquadrar na categoria dos sistemas abertos.

4. As entradas de energia no SCU são de natureza térmica (oriundas da fonte primária de energia de toda a Terra-Sol), implicando componentes dinâmicas inequívocas determinadas pela circulação atmosférica, e decisivas para a componente hídrica englobada nesse conjunto.

5. A avaliação dessa entrada de energia no SCU deve ser observada tanto em termos quantitativos como, especialmente, em relação ao seu modo de transmissão. 
6. A estrutura interna do SCU não pode ser definida pela simples superposição ou adição de suas partes (compartimentação ecológica, morfológica ou funcional urbana), mas somente por meio da íntima conexão entre elas.

7. O conjunto-produto do SCU pressupõe vários elementos que caracterizam a participação urbana no desempenho do sistema. Sendo variada e heterogênea essa produção, faz-se mister uma simplificação, classificatória, que deve ser constituída através dos canais de percepção humana.

8. A natureza urbana no SCU implica em condições especiais de dinamismo interno consoante o processo evolutivo do crescimento e desenvolvimento urbano, uma vez que várias tendências ou expressões formais de estrutura se sucedem ao longo do processo de urbanização

9. O SCU é admitido como passível de autorregulação, função essa conferida ao elementos homem urbano que, na medida em que conhece e é capaz de detectar suas disfunções, pode, através do seu poder de decisão, intervir e adaptar o funcionamento do mesmo, recorrendo a dispositivos de reciclagem e/ou circuitos de retroalimentação capazes de conduzir o seu desenvolvimento e crescimento seguindo metas pré-estabelecidas.

10. Pela possibilidade de interferência autorreguladora, acrescenta-se ao SCU como sistema aberto, aquelas propriedades de entropia negativas pela sua própria capacidade de especialização dentro do crescimento através de processos adaptativos, podendo ser qualificado, assim, como um sistema morfogenético.

Monteiro (2003) enfatiza que a cidade é vista como um sistema aberto que recebe entrada e saída de energia, onde há a presença da ação humana sobre o sistema, configurando a relação clima-cidade como díspar em cada análise. Deste modo, o SCU proposto pelo autor busca agregar tal interação dinâmica como contexto para a análise dos fatores termodinâmicos, hidro meteóricos e físico-químicos.

\section{Sistema Clima Urbano}

Na criação do SCU, Monteiro (1976, 2003) estabeleceu um sistema constituído por 4 (quatro) fases distintas, sendo Importação (de energia ao sistema), Transformação (de energia dentro do sistema), Incorporação (da energia transformada no sistema) e Exportação (regresso da energia transformada no sistema), com 3 (três) canais de percepção, sendo eles o FísicoQuímico (qualidade do ar), o Hidro meteórico (impacto meteórico) e o Termodinâmico (conforto térmico).

No que concerne às discussões sobre os fatores termodinâmicos, estes são baseados na relação de conforto térmico (sensação e desempenho humano) do usuário na cidade. Este fator é, fundamentalmente, estudado pelos arquitetos e urbanistas, visando o conforto térmico do usuário na cidade e proposições de melhorias por meio de estratégias arquitetônicas para sanar tal ação.

$\mathrm{Na}$ questão hidrometeórica é analisada a relação dos impactos, como chuva, neve, granizo, dentre outros, sobre a cidade e a relação de sua influência no ordenamento urbano. 
Thyago Phellip França Freitas

Tal fator está atrelado à capacidade de suporte do espaço citadino de sofrer impactos concentrados em curto espaço de tempo e de não sofrer desordens em seu meio.

No fator físico-químico a análise se faz presente na relação com a poluição do ar na cidade e suas implicações à saúde do cidadão, com as circulações atmosféricas (inversões térmicas) presentes, bem como os deslocamentos horizontais e verticais da atmosfera que ajudam a promover episódios considerados críticos de poluição atmosférica. (MONTEIRO, 2003).

Monteiro (1976; 2003) agregou ainda o fator antrópico (homem) no meio físico das pesquisas sobre o clima, pois o mesmo tem estrita relação com estas dimensões, afetando e sendo afetado por meio dos canais de percepção, ou seja, as interações urbanas sofrem influência e são influenciadas pela qualidade do ar, dos impactos hidrometeóricos e de temperatura.

Deste modo, o autor aprofundou a discussão metodológica sobre o "air within city" e deu embasamento teórico e experimental para vários pesquisadores da área de Arquitetura e Urbanismo. Dentre os inúmeros trabalhos que buscaram a sustentação metodológica no SCU podem ser citados, a título de exemplos, as contribuições de Ortiz (2011) em Cândido Mota, Paz (2009) em Palmas, Mendonça (1994) em Londrina, Pitton (1997) em Rio Claro, Sezerino (1990) em Florianópolis, Souza (2013) em Ourinhos entre outros.

Ortiz (2011) expõe que o SCU contempla desde os fatores mais amplos e complexos até os mais simples e restritos, de forma integrada e não fragmentada da cidade. Com base nisto, percebe-se que o sistema corrobora para que o pesquisador faça uma análise científica do método indutivo e/ou dedutivo, com dinamismo, dentro de uma abordagem adaptativa e sistêmica, podendo assim, desenvolver um sistema de análise de acordo com a necessidade do objeto estudado.

Desta forma, observa-se que o clima urbano é resultado de um espaço urbanizado somado às características dos sistemas regionais em que ele se encontra com vistas à contribuição para os usuários do espaço urbano ensejando melhoria na qualidade de vida destes.

\section{Aos Geógrafos e Arquitetos}

A áreas de Arquitetura e Urbanismo e Geografia, por vezes têm os mesmos objetos de investigação e, desta forma, há a aproximação entre os seus profissionais, fazendo-os 
Thyago Phellip França Freitas

buscarem respostas que, embasadas nas áreas em questão, culmine com a contribuição da melhoria dos espaços transformados pela vivência humana.

Embora a Arquitetura e a Geografia tenham uma certa proximidade, vez que se utilizam dos mesmos elementos em seus fazeres, por vezes há divergências entre os pesquisadores de cada área como relata Monteiro (2010) ao destacar que ao propor esta nova metodologia de pesquisa do clima urbano, ele foi negligenciado pelos seus colegas geógrafos, pois eles estavam mais preocupados com a geografia física e não com a humanística, ou seja, uma geografia que englobasse o homem como parte do processo gerado pelo ambiente e sendo influenciado por este.

$\mathrm{O}$ autor destaca ainda que os que mais aceitaram a sua proposta foram os arquitetos e urbanistas, uma vez que o SCU aborda questões de conforto térmico do usuário, e com base nele poderiam propor ações de mitigação das chamadas ilhas de calor, objeto de estudo de muitos arquitetos, uma vez que há interdisciplinaridade e/ou convergência das duas áreas distintas e que essa junção visa contribuir com a produção de conhecimentos sobre o clima urbano.

Com a aceitação dos ditos "ordenadores da cidade", Monteiro (2010) destaca que estes fizeram os primeiros experimentos na área de clima urbano focados na questão arquitetônica e sua influência no meio. Destaca ainda autores como Assis (2001) e Sampaio (1981), ambos arquitetos, que trabalharam a climatologia urbana e o conforto térmico associados ao elemento urbano e homem, buscando assim descer a escala de análise e verificar alterações ao nível do pedestre.

Os geógrafos só foram aplicar seus primeiros experimentos, 17 anos depois da proposição do SCU (MONTEIRO, 2006) fato este que sempre causou intriga no autor. Pois os pesquisadores destas áreas utilizam o mesmo espaço de pesquisa e suas transformações urbanas e naturais com abordagem diferentes e dissociadas com vistas a entender o homem para produzir conhecimentos e, consequentemente, melhoria no conforto término e na qualidade de vida das pessoas.

Monteiro (2003) destaca que este número vem crescendo vertiginosamente, prova disto é que quando da realização do I Seminário de Brasileiro de Climatologia Geográfica em 1994, onde foram apresentadas 38 publicações acerca do clima urbano, totalmente diferente das abordagens recentes onde esta é uma das áreas com maior procura pelos profissionais de ambas as áreas (arquitetos e geógrafos). A resistência a esta nova metodologia brasileira foi 
grande por parte de alguns pesquisadores, uma vez que todos os estudos de clima eram estudados sob o ponto de vista do clima europeu no clima tropical brasileiro.

Assis (2006) destaca que os estudos em torno de clima urbano são $5 \%$ voltados à aplicação de modelos existente, entre eles o modelo de Monteiro (1976), e destes somente $23 \%$ são voltados ao conforto térmico do usuário. Sendo assim, a autora reforça que tais estudos são voltados para os aspectos da qualidade do ambiente construído e correlacionados a um planejamento físico e a um projeto urbano eficiente. Destaca ainda que os estudos são somente de casos específicos, o que implica dizer que só tem validação na cidade pesquisada e não no contexto geral.

\section{Considerações finais}

Ressalta-se que a proposta de Monteiro (1976) é um subsídio eficaz na questão de estudos do clima urbano no Brasil, uma vez que é uma metodologia brasileira e voltada o clima tropical do nosso país, contudo deve-se atentar pra a formulação de novos modelos metodológicos e não a aplicação contínua do SCU, uma vez que este aparato metodológico, além de servir como modelo, pode proporcionar novos estudos e possivelmente novas metodologias.

As metrópoles estão passando constantemente por avaliações da metodologia do SCU, em seus 3 canais de percepção, e possuem infinitas variáveis devido ao complexo sistema no qual estão inseridos, além da extensão territorial, e muitas vezes o resultado e as conclusões já são conhecidos, não são conclusivos ou a aplicação de estratégias fica no campo das abstrações e não no campo da aplicação.

Desta forma, entende-se que há possibilidade de novos estudos em pequenas e médias cidades, uma vez que estas, além de possuírem menor extensão territorial, possuem poucas variáveis, o que implica em uma mensuração de dados mais rápida e com maior abrangência e efetividade de proposições, bem como o resultado das conclusões ou proposições torna-se um instrumento capaz de orientar o crescimento futuro destas urbes.

\section{Notas}

\footnotetext{
${ }^{1}$ Relativo ao homem ou ao período de existência do homem na Terra e às modificações por ele provocadas no meio ambiente (MICHAELIS, 2018).
} 
Thyago Phellip França Freitas

\section{Referências}

ASSIS, E.S. Aplicações da Climatologia Urbana no Planejamento da Cidade: Revisão dos Estudos Brasileiros. Revisa Rua, v 09, n. 1, pág. 20-25, Salvador, nov. 2006.

ASSIS, E. S. Impactos da forma urbana na mudança climática: método para a previsão do comportamento térmico e melhoria de desempenho do ambiente urbano. Tese (Doutorado em Arquitetura e Urbanismo) - Faculdade de Arquitetura e Urbanismo, Universidade de São Paulo, São Paulo, 2000.

BARBUGLI, R. A.; RORIZ M. Mapeamento Das Temperaturas Do Ar Na Cidade De Araraquara, São Paulo, Brasil. Encontro Nacional Sobre Conforto Do Ambiente Construído, 8., 2005, Maceió, AL; Encontro Latino-Americano Sobre Conforto Do Ambiente Construído, 4., 2005, Maceió, AL,2005, Maceió, AL, 2005. p. 112-122.

BENEVOLO, L. A história da cidade. $3^{\circ}$ ed., São Paulo: Perspectiva, 2009.

BertalanfFy, L.V. The Theory of Open Systems in Phsysics and Biology. Science n.111, 1950. DOI: http://dx.doi.org/10.1126/science.111.2872.23

BORJA, J; CASTELlS, M. A cidade como atores políticos. Revista Novos Estudos, CEBRAP, $\mathrm{n}^{\mathrm{o}} \quad 45$ jul. 1996, p. 152-166 Disponível em < http://www.novosestudos.com.br/v1/files/uploads/contents/79/20080626_as_cidades_como_a tores.pdf >. Acesso em 02 ago. 2014.

CHANDLER, T.J. The Climate of London. London, Hutchinson University Library Publishers, 1965.

LANDSBERG, H.E. The Cimate of Towns. In: THOMAS, W.E., EcMan's Role in changing the face of heart. The WennerGreen Foundation Anthropological Research. The University of Chicago Press, 1956.

MONTEIRO, C. A. F. Teoria e clima urbano. São Paulo: IGEOG/USP, 1976 (Série Teses e Monografias, n. 25).

Teoria e Clima Urbano. In: MONTEIRO, C. A. F; MENDONÇA, F. (org.). Clima Urbano. Ed. Contexto. São Paulo, 2003, p.9-65.

Por um suporte teórico e metodológico para estimular estudos geográfico se clima urbano no Brasil. Revista Geosul. No09, ano V, $1^{\circ}$ semestre de 1990. Florianópolis, 1990.

A cidade como processo derivador ambiental e a geração de um clima urbano. Revista Geosul. Nº9, ano V, $1^{\circ}$ semestre de 1990. Florianópolis, 1990.

Some aspects of the urban climate of tropical South America: the Brazilian contribution. In: Technical Conference on Urban Climatology and its applications with special regard to tropical areas, 1984, Ciudad de Mexico, Mexico. Proceedings. Geneva: WMO No. 652, 1986, p. 166-197. 
O CLIMA URBANO DAS CIDADES E SUAS INTERAÇÕES COM A ARQUITETURA E A GEOGRAFIA

Thyago Phellip França Freitas

Entrevista com Carlos Augusto de Figueiredo Monteiro [EDITORIAL].

Revista Rua, v 09, n. 1, pág. 100-107, Salvador, nov. 2006.

Entrevista com o Professor Carlos Augusto Figueiredo Monteiro. Revista Discente Expressões Geográficas, nº 06, ano VI, p. 01 - 18. Florianópolis, junho de 2010.

ROMERO, M. A. B. Princípios bioclimáticos para o desenho urbano. São Paulo: Projeto, 1988. 128p. 